\title{
Compact Planar Inverted F Antenna (PIFA) for Smart Wireless Body Sensors Networks ${ }^{+}$
}

\author{
Mohammad Monirujjaman Khan \\ Department of Electrical and Computer Engineering, North South University, Dhaka 1229, Bangladesh; \\ monirujjmaan.khan@northsouth.edu; Tel.:+8801779006296 \\ + Presented at the 7th International Electronic Conference on Sensors and Applications, 15-30 November \\ 2020; Available online: https://ecsa-7.sciforum.net/.
}

Published: 15 November 2020

\begin{abstract}
In this paper a dual band, a dual band Planar Inverted F antenna (PIFA) is designed for wireless communication intended to be used in wireless body sensor networks. The designed PIFA operates at two different frequency bands, $2.45 \mathrm{GHz}$ (ISM band) and $5.2 \mathrm{GHz}$ (HiperLAN band). In body-centric wireless networks antennas need to be integrated with wireless wearable sensors. An antenna is an essential part of wearable body sensor networks. For on-body communications antennas need to be less sensitive from human body effects. For body-centric communications wearable devices need to communicate with the devices located over the surface and also there is a need of communication from on-body devices to off-body units. Based on this need a dual band planar inverted $\mathrm{F}$ antenna is designed which works at two different frequency bands, i.e., $2.45 \mathrm{GHz}$ and $5.2 \mathrm{GHz}$. The $2.45 \mathrm{GHz}$ is proposed for establishing communication among the wireless sensor devices attached on the human body while $5.2 \mathrm{GHz}$ is proposed for the communications form onbody to off-body devices. The proposed antenna is very compact and due to having ground plane at the backside it shows less sensitive to the effects of the human body tissues. Computer Simulation Technology (CST) microwave studio ${ }^{\mathrm{TM}}$ was used for antenna design and simulation purposes. Performance parameters such as return loss, bandwidth, radiation pattern and efficiency of this antenna are shown and investigated. These performance parameters of the proposed antenna have been investigated at free space and close proximity to the human body. Simulation results and analysis show that the performance parameters of the proposed very good results at both frequency bands. Due to its compact size, less sensitive to the human body tissues and dual band functionality, it will be a good candidate for wireless wearable body sensor networks.
\end{abstract}

Keywords: compact PIFA; wireless body sensors networks; CST; ISM; HiperLAN; on-body; of-body

\section{Introduction}

In Wireless Body Sensors Networks (WBSANs), the wireless connectivity between body-centric units is provided through the placement of sensor and compact antennas. Recently, an amassed interest in body centric wireless communications has made the research field very popular. Wireless sensor and body area networks are striking solutions that can be used in healthcare applications, which will qualify constant monitoring of health data and constant access to the patient. In WBSANs communication, the wireless connectivity between body-centric units is provided through the deployment of sensor and compact antennas $[1,3,8]$. Body-worn antennas can suffer from reduced efficiency and gain due to electromagnetic immersion in tissue, radiation pattern fragmentation, variations in feed point impedance and frequency detuning $[1,3,8,16,18]$. It was predicted that wireless sensor solutions could save $\$ 25$ billion worldwide in annual healthcare costs by plummeting hospitalizations and extending independent living for the elderly [1]. 
In common healthcare monitoring scenarios, it is very essential for the antenna to communicate among the devices on the body and off-body devices. The on-body-communications defines the communication among body mounted devices and off-body communication defines the communication from body worn devices and base units or mobile devices located in surrounding environments [10]. Lately, designing wearable antennas has been increasing interest in research and development for body sensor networks [2,3,8,16,18]. Planar Inverted-F Antenna (PIFA) has been prevailing for handling wireless devices because of their many characteristics such as simple design, lightweight, low cost, compactness, conformable nature and reliable performance [2-4]. Previously, many researchers have designed wearable antennas for on-body communications at $2.45 \mathrm{GHz}$ and ultra-wideband (UWB) at 3.1 10.6 GHz [8-16]. However, antennas of wireless body sensors networks need to communicate body mounted devices and also off the body devices.

In this paper, a dual band planar inverted F antenna (PIFA) is designed for both on and off-body communications. Performance of proposed antenna is studied in free space and on the three layers human body model. The antenna operates at two frequency bands, i.e., $2.45 \mathrm{GHz}$ (ISM band) and 5.2 $\mathrm{GHz}$ (Hiperlan band). The $2.45 \mathrm{GHz}$ is designed for communication among the devices attached on the human body and $5.2 \mathrm{GHz}$ is used for the communication from body mounted devices to off-body other devices.

\section{Proposed PIFA Antenna Design}

The proposed PIFA is comprises of a rectangular planar element located above a ground plane, a shorting pin and feeding pin for the planar element. Computer Simulation Technology (CST) microwave studio ${ }^{\mathrm{TM}}$ software was used for the design and results of the antenna. The software design and schematic drawing of the dual band PIFA is presented in Figure 1. The antenna was designed on FR4 substrate with a thickness of $1.52 \mathrm{~mm}$ and a relative permittivity of 4.6. In this proposed design there is full ground plane of the antenna. The size of the ground plane is $63 \mathrm{~mm} \times 34 \mathrm{~mm}$ with a total height of the antenna $6.92 \mathrm{~mm}$.
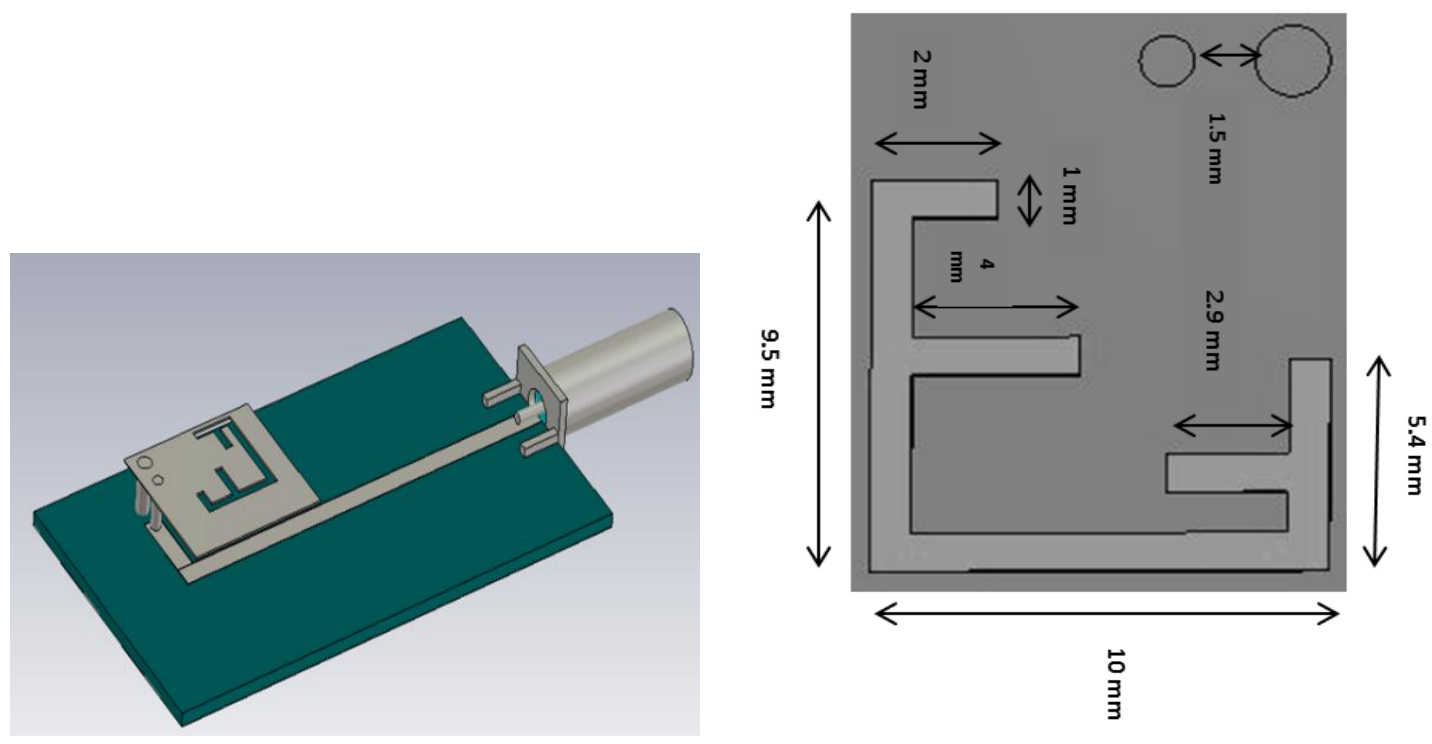

Figure 1. Developed antenna software design of the PIFA, and schematic diagram of the PIFA.

Microstrip feed line was used to excite this antenna. The gap between the shorting pin and the feeding pin is $1.5 \mathrm{~mm}$. The aim of the shorting pin of the PIFA is to reduce the size of the antenna and to achieve the impedance matching $[7,9,17]$. The radiating element of rectangular PIFA works at the lower frequency band $(2.45 \mathrm{GHz})$. The double F shape slits are introduced on the antenna structure with a view to achieve $5.2 \mathrm{GHz}$ band. The bandwidth of the dual band PIFA can be achieved by 
changing radiating element size, changing the width of the shorting pin, and adding slot on the ground plane.

\section{Results and Analysis}

The antenna first was designed using CST software as mentioned earlier. The free space design performance parameters of the antenna were extracted and then the antenna was placed on the three layers human body model in order to study the effects of human body on the antenna performance parameters. Figure 2 shows the antenna on the designed three layers human body model. In this study, three layers (skin, fat and muscle) of rectangular human model is created with human tissues electrical properties defined at $2.45 \mathrm{GHz}$ and $5.2 \mathrm{GHz}$, respectively. For $2.45 \mathrm{GHz}$, relative permittivity and conductivity used for skin, fat and muscle are 38.007 and $1.464(\mathrm{~S} / \mathrm{m}) ; 5.2801$ and $0.10452(\mathrm{~S} / \mathrm{m}) ; 52.729$ and $1.7388(\mathrm{~S} / \mathrm{m})$ respectively. Similarly for $5.2 \mathrm{GHz}$, relative permittivity and conductivity for skin, fat and muscle are 35.618 and $3.2106(\mathrm{~S} / \mathrm{m}) ; 5.0113$ and $0.25407(\mathrm{~S} / \mathrm{m}) ; 49.292$ and $4.2556(\mathrm{~S} / \mathrm{m})$ respectively [19]. The distance between the antenna and the three layer human body model was $8 \mathrm{~mm}$.
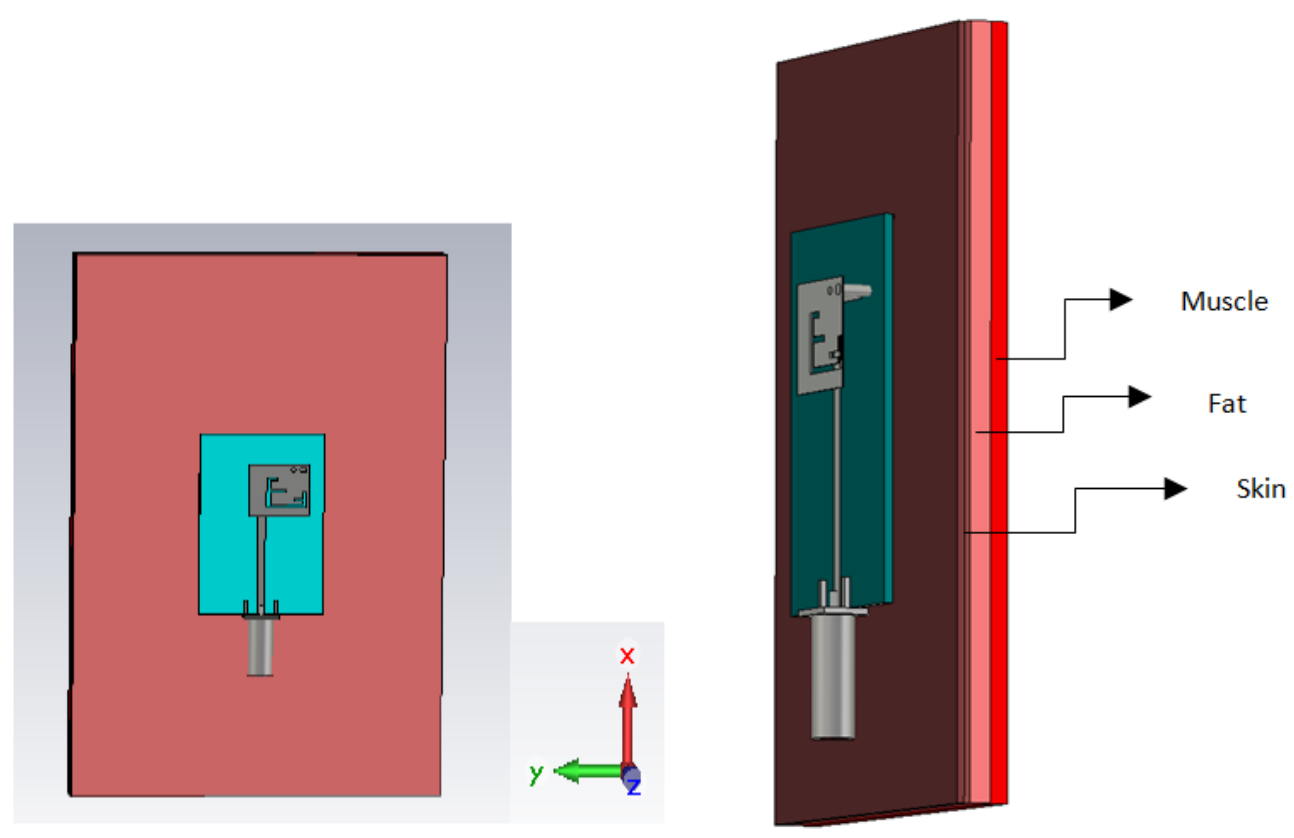

Figure 2. Antenna on three layers human body model.

The free space and on-body return loss response of the antenna is presented in Figure 3. In Figure 3 it is noticed that the antenna works at two different frequencies which are $2.438 \mathrm{GHz}$ (ISM Band) and $5.2 \mathrm{GHz}$ (HiperLAN band). The antenna shows good return loss responses at both frequency bands of operations. Very slight frequency detuning is noticed which is due to the dielectric properties of human body lossy tissues. Interesting is that the return loss improves at both frequencies when placed on the human three layer model. Rerun loss and frequency is very less sensitive on the human body which shows suitability of the antenna for WBSNS. 


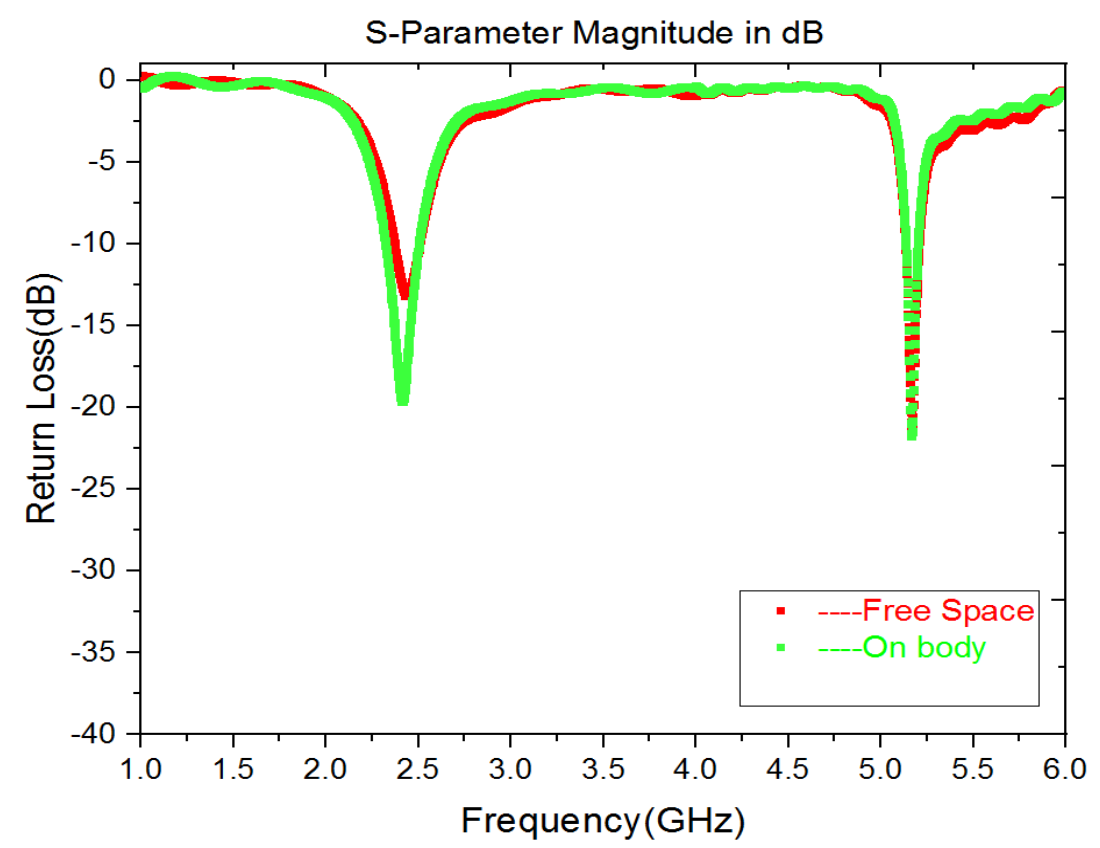

Figure 3. Free space and on-body return loss responses of the PIFA.

If frequency is out of the range there will be serious problem and the return loss shows power transmission capability. Since the rerun losses in both cases are more than $-10 \mathrm{~dB}$ means more than $90 \%$ power will be transferred providing the fact that the antenna will be good for power efficient communication in WBSNs. The antenna shows $136.3 \mathrm{MHz}$ bandwidth at $-10 \mathrm{~dB}$ impedance at lower frequency and at higher frequency the bandwith is noticed to be $73 \mathrm{MHz}$. Placing the antenna on the body bandwidth increases at the lower frequency at about $44 \mathrm{MHz}$ and at higher frequency sight (6.6) $\mathrm{MHz}$ reduction is observed. The antenna shows required ISM band bandwidth (88 MHz) even placing on the body. List of detail results about antenna parameters are listed in Table 1.

The PIFA shows a maximum peak gain of $3.77 \mathrm{dBi}$ at $2.45 \mathrm{GHz}$ while $2.53 \mathrm{dBi}$ gain is noticed at $5.2 \mathrm{GHz}$. After the simulation on the three layers human body model a decrease of $0.9 \mathrm{~dB}$ gain is noticed at lower band but increase of $1.21 \mathrm{~dB}$ is noticed for higher frequncy band. Even on the body the antenna shows excellent gains which are enough for both frequany bands to transmit power efficiently with efficient link power. The free space radiation efficiency of the proposed PIFA is $98.64 \%$ and $94.43 \%$ at lower and higher bands, respectively.

Table 1. Comparison of performance parameters of the PIFA (free space and on-body).

\begin{tabular}{lcccc}
\hline \multicolumn{1}{c}{ Parametrs } & $\begin{array}{c}\text { Lower Band(2.45 } \\
\text { GHz)Free Space }\end{array}$ & $\begin{array}{c}\text { HigherBand(2.45 } \\
\text { GHz) On-body }\end{array}$ & $\begin{array}{c}\text { Higher Band(5.2 } \\
\text { GHz)Free Space }\end{array}$ & $\begin{array}{c}\text { HigherBand(5.2 } \\
\text { GHz)On-body }\end{array}$ \\
\hline Resonance $f_{c}$ & 2.4382 & 2.4131 & 5.168 & 5.1659 \\
(GHZ) & -13.16 & -19.658 & -21.427 & -21.762 \\
Return Loss $(\mathrm{dB})$ & 136.3 & 180.7 & 73 & 66.4 \\
Bandwidth(MHz) & 3.772 & 2.775 & 2.537 & 3.748 \\
Gain $(\mathrm{dB})$ & 98.64 & 61.68 & 94.43 & 69.43 \\
Efficiency \% & & & \\
\hline
\end{tabular}

When it is placed on the body due to lossy human body tissues reduction of $36.98 \%$ at $2.45 \mathrm{GHz}$ and $25 \%$ at $5.2 \mathrm{GHz}$ are noticed. Although the reduction of radiation efficiency is noticed but still the radiation efficiency are very good for both bands. The less reduction of radiation efficiency is due the ground plane of the antenna at the backside that acts as a shield between the body and the antenna.

Free space and on-body radiation patterns at both frequency bands of the antenna are presented in Figures 4 and 5. From the graph it is noticed that when antenna simulated on the human body the radiation patterns of the antenna at both bands do not deform but power levels varies slightly. The 
results of the radiation patterns at both frequencies of the PIFA show that the antenna will show good performance for establishing power efficient communication among the devices located on the body and also off-body devices.

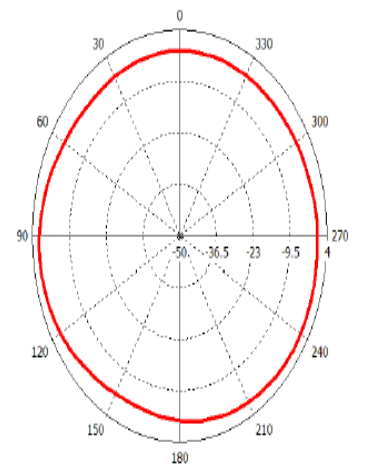

(a)

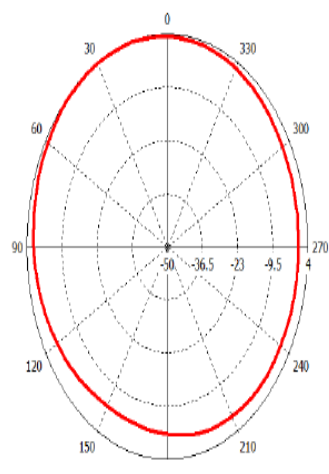

(b)

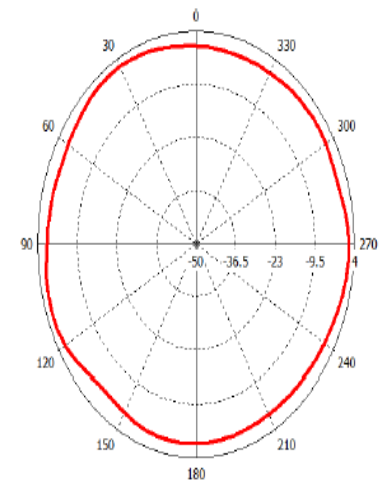

(c)

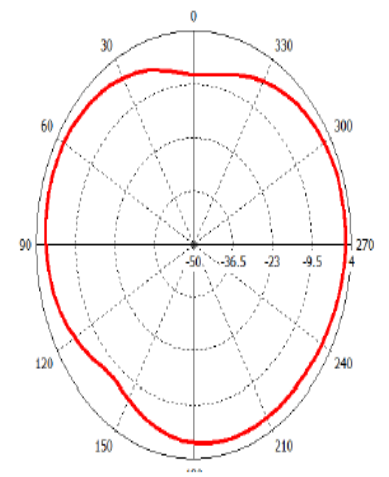

(d)

Figure 4. Free space radiation pattern at (a) XY Plane at $2.438 \mathrm{GHz}$ (b) YZ Plane at $2.438 \mathrm{GHz}$ (c) XY Plane at 5.168 GHz (d) YZ Plane at 5.168 GHz.

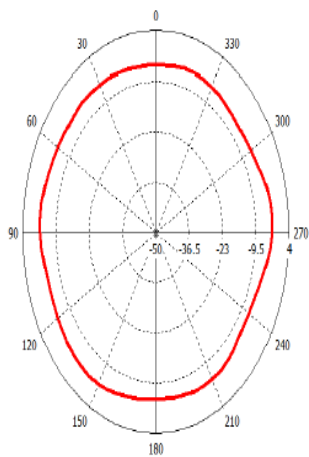

(a)

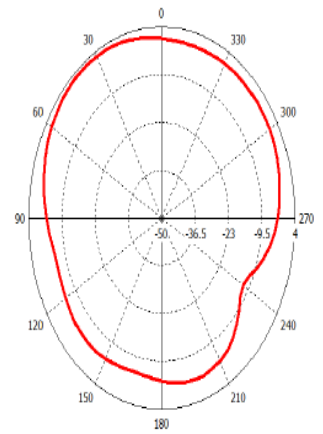

(b)

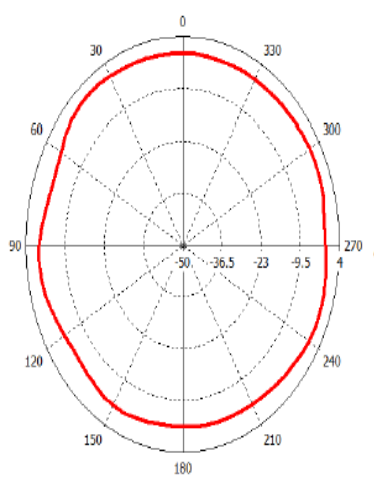

(c)

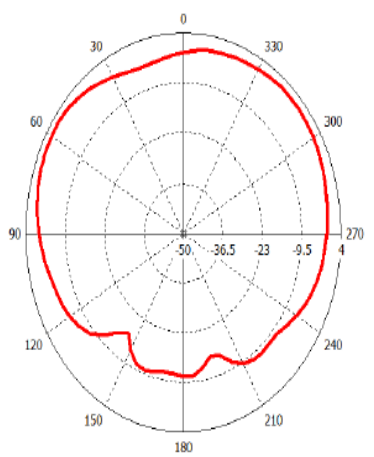

(d)

Figure 5. On-body radiation pattern at (a) XY Plane at $2.438 \mathrm{GHz}$ (b) YZ Plane at 2.438 GHz (c) XY Plane at $5.168 \mathrm{GHz}(\mathbf{d}) \mathrm{YZ}$ Plane at $5.168 \mathrm{GHz}$.

\section{Conclusions}

Simulated compact dual band PIFA antenna design is presented. Free space and on-body performance parameters of this antenna for the communication among on-body devices and also offbody devices are investigated and analyzed. The antenna is proposed for power efficient communications for the wireless body area sensor networks. Having full ground plane at the backside of the antenna gives very less sensitive from the human body lossy tissues when placed on the human body there layers model. Results and analysis show very good free space and on-body performance parameters of the antenna. Due to its compact size, dual band functionality and very good on-body results it will be a suitable candidate for both on-body and off-body communications in wireless body sensors networks.

Funding: The project was done self-funded. It is simulation based work and the author has designed and simulated the antenna himself.

Acknowledgments: Author would like to thank North South University for providing him an office space and a desktop for doing the simulation and research work after his teaching hours.

Conflicts of Interest: The author of this paper declares no conflicts of interest. 


\section{References}

1. WSN for Healthcare: A Market Dynamics Report. Available online: http://www.onworld.com/healthcare.index.html (accessed on 7 August 2008).

2. Hall, P.S.; Hao, Y. Antennas and Propagation for Body Centric Wireless Communications; Artech House: Boston, MA, USA; London, UK, 2006.

3. Liu, Z.D.; Hall, P.S.; Wake, D. Dual-Frequency Planar Inverted-F Antenna. IEEE Trans. Antennas Propagat. 1997, 45, 1451-1458.

4. Misran, N.; Yunus, M.M.; Islam, M.T. Small Dual-Band Planar Antenna with Folded Patch Feed. J. Appl. Sci. Res. 2010, 6, 1975-1980.

5. Hsiao, F.R.; Chen, H.T.; Chiou, T.W.; Lee, G.Y.; Wong, K.L. A Dual-Band Planar Pnverted-F Patch Antenn with a Branch-Slit. Microw. Opt. Technol. Lett. 2002, 32, 310-312.

6. Bahl, I.J.; Bhartia, P. Microstrip Antennas; Artech House: Dedham, MA, USA, 1980.

7. Guha, D.; Antar, Y.M.M. Microstrip and Printed Antennas: New Trends, Techniques and Applications; WileyBlackwell: Hoboken, NJ, USA, 2011; ISBN-10: 0470681926.

8. Otto, C.; Milenkovic, A.; Sanders, C.; Jovanov, E. System A rchitecture for a Wireless Body Area Network for Ubiquitous Healthcare Monitoring. J. Mobile Multimed. 2006, 307-326.

9. Stutzman, W.L.; Thiele, G.A. Antenna Theory and Design; John Wiley \& Sons, Inc.: Hoboken, NJ, USA, 1998.

10. Hall, P.S.; Hao, Y. Antennas and Propagation for Body-Centric Wireless Communications, 2nd ed.; Artech House: Norwood, MA, USA, 2006.

11. Alomainy, A.; Hao, Y.; Davenport, D.M. Parametric Study of Wearable Antennas Varying Distances from the Body and Different On-Body Positions; IET: London, UK, 2007; pp. 84-89.

12. Scanlon, W.G.; Evans, N.E. Numerical analysis of body worn UHF antenna systems. Electron. Common. Eng. J. 2001, 13, 53-64.

13. Sun, Y.Y.; Cheung, S.W.; Yuk, T.I. Planar monopoles with different radiator shapes for UWB Body-Centric Wireless Communications. J. Eng. 2013, doi:10.1155/2013/683428.

14. Abbasi, Q.H.; Khan, M.M.; Liquate, S.; Kamran, M.; Alomainy, A.; Hao, Y. Experimental investigation of ultra-wide band diversity techniques for on-body radio communications. Prog. Electromagn. Res. C 2013, 34, 165-181.

15. Khan, M.M.; Abbasi, Q.H.; Alomainy, A.; Hao, Y. Performance of ultra-wideband wireless tags for on-body radio channel Characterisation. Int. J. Antennas Propag. 2012, 2012, 1-10.

16. Cotton, S.L.; Scanlon, W.G. An experimental investigation into the influence of user state and environment on fading characteristics in wireless body area networks at $2.45 \mathrm{GHz}$. IEEE Trans. Wirel. Commun. 2009, 8 , 6-12.

17. Rappaport, T.S. Wireless Communications: Principles and Practice; Prentice Hall Communications Engineering and Emerging Technologies Series; Prentice Hall PTR: NJ, USA, 1999.

18. Patel, M.; Wang, J. Applications, Challenges, and Prospective in Emerging Body Area Networking Technologies. IEEE Wirel. Commun. 2010, 17, 80-88.

19. Calculation of the Dielectric Properties of Body Tissues. Institute for Applied Physics, Italian National Research Council. Available online: http://niremf.ifac.cnr.it/tissprop/(accessed on 5 November 2010).

Publisher's Note: MDPI stays neutral with regard to jurisdictional claims in published maps and institutional affiliations.

(C) 2020 by the authors. Submitted for possible open access publication under the terms and conditions of the Creative Commons Attribution (CC BY) license (http://creativecommons.org/licenses/by/4.0/). 